\title{
Evaluation of the Nephroprotective Effect of Sambucus Nigra Total Extract in a Rat Experimental Model of Gentamicine Nephrotoxicity
}

\author{
RODICA UNGUR ${ }^{1}$, ROXANA BUZATU2 ${ }^{2}$, RADU LACATUS ${ }^{3}$, ROBERT CRISTIAN PURDOIU ${ }^{3}$, GEORGIANA PETRUT4 $^{4}$, RAZVAN CODEA $^{3 *}$, \\ ORSOLYA SARPATAKY ${ }^{3}$, ALEXANDRA BIRIS ${ }^{3}$, CRISTIAN POPOVICI ${ }^{3}$, MIRCEA MIRCEAN ${ }^{3}$, DELIA BUNEA J IVANESCU ${ }^{1}$, \\ COSMIN PESTEAN ${ }^{3}$, LIVIU OANA ${ }^{3}$ \\ IUniversity of Medicine and Pharmacy luliu Hateganu, Faculty of General Medicine, 13 Isac Emil Str., 400090, Cluj-Napoca, \\ Romania \\ ${ }^{2}$ University of Medicine and Pharmacy Victor Babes, Faculty of Dental Medicine, 2 Eftimie Murgu Sq, 300041, Timisoara, Romania \\ ${ }^{3}$ University of Agricultural Science and Veterinary Medicine, Faculty of Veterinary Medicine, 3-5 Manastur Str., 400372, Cluj- \\ Napoca, Romania \\ ${ }^{4}$ University of Agricultural Science and Veterinary Medicine, Faculty of Food Science, 3-5 Manastur Str., 400372, Cluj-Napoca, \\ Romania
}

\begin{abstract}
Elderflower contains flavonoles, the most important of them being quercetin. These molecules have an important antioxidant effect. The goal of our study was to evaluate which conservation technique of elderflower results the highest concentration of rutin and and phenolic compounds. Further we evaluated the protective effects of these extracts against nephrotoxicity induced by gentamicin in rats. Sambucus nigra extract demonstrates nephroprotective effects in gentamicin-induced renal toxicity, significantly improving outcome and evolution in rats.
\end{abstract}

Keywords: elderflowers, rats, gentamycin, nephoprotective effects

Renal failure describes a broad spectrum set of systemic dysfunctions ranging from umoral changes, detectible only using paraclinical exams, to uremic syndrome that causes multiple organic implications.

Regarding the main causes of renal failure it is well known and proved that type 1 and type 2 diabetes, arterial hypertension, arterial hypotension and the toxicity of certain substances play a major role in the development of renal lesions, leading to glomerular and intestitial damage [13]. Other studies describe that disturbances in lipidic metabolism (hypercholesterolemia), due to a cholesterolrich diet, can also worsen the renal dysfunction $[4,5]$.

The main flavonoles in elderflower are represented by glycosides of quercitin, kaempferol and isorhamnetin. Nevertheless, the most important flavonol extracted form elderflower is quercetin-3-rutinoside that along with kaempferol-3-rutinoside and isorhamnetin-3-rutinoside represents more than $90 \%$ of the total flavonoids in most analyzed genotypes. Other classes of polyphenolic compounds found in the elderflower, besides flavonoids, are flavonols (catechin, epicatechin, procyanidin trimer), and n-hydroxycinnamic acids (neochlorogenic acid, cryptochlorogenic acid, 3-5ferroylchinonic acid, dicyclohexylquinic acid, 1,5-di-formylquinic acid [6].

The main objective of the present study is to evaluate the nephroprotective effect of phenolic compounds found in elderflower inflorescences harvested from local spontaneous flora, in an experimental model of gentamicin induced nephrotoxicity in Wistar rats.

\section{Experimental part}

Materials and methods

Elderflower collection and processing

To carry out the research of our experiment, we used organic material represented by elderflower inflorescences (Sambucus nigra L), harvested from the local spontaneous flora found in the surroundings of Cluj-Napoca, Romania. Part of the harvested inflorescences was frozen at $-18 \mathrm{C}^{\circ}$, in vacuum packed polyethylene bags, and another part was dried for 10 days, in a dark environment.
Quantitative determination of phenolic compounds in elderflowers

Regarding the determination of phenolic compounds in the N4FU and N4FC study samples (inflorescences without peduncle), it was performed according to the method proposed byMikulic-Petkovsek et al., 2015 [7], with some adjustments. Ethanol was the solvent of choice, where $1 \mathrm{~g}$ of the ground sample was added, homogenized and then allowed to stand for $24 \mathrm{~h}$ at 2-3C $\mathrm{C}^{\circ}$. Using the Laborata 4010 Digital Heidolph rotary evaporator, the sample was brought to dryness and the resulting extract recovered in $10 \mathrm{~mL}$ of ethanol, filtered through $0.45 \mu \mathrm{m}$ Millipore filters and stored at $-20 \mathrm{C}^{\circ}$ until analysis.

The analyses were performed according to the method described by Filip et al., 2017 [ 8], using a J asco (Japan) High Performance Liquid Chromatograph (HPLC) equipped with an HPLC pump, column thermostat, a ternary gradient unit, a UV / VIS detector and a $20 \mu \mathrm{L}$ sample loop injection valve (Rheodyne) ( $50 \mathrm{~mL}$ Hamilton Rheodyne syringe) of the sample.The processing of the obtained data was realized with the ChromPass software. Flavonoid and phenolic acid separation were performed on a Lichrosorb RP-C18 column $(25 \times 0.46 \mathrm{~cm})$ at column temperature of $22^{\circ} \mathrm{C}$ and UV detection at $270 \mathrm{~nm}$. The mobile phase was a mixture of methanol (grade A, HPLC grade) and $0.1 \%$ formic acid solution (Millipore ultrapure water) and a gradient was applied according to the following method: 0-10 min, linear gradient $10-25 \% A ; 10-25$ min, linear gradient $25-30 \%$ A; 25-50 min, linear gradient $35-50 \%$ A; $50-70 \mathrm{~min}, 50 \%$ isocratic $A$. The flow rate was $1 \mathrm{~mL} / \mathrm{min}$ and the injector volume were $20 \mu \mathrm{L}$. All compounds were identified by comparing their elution times with those of the standard compounds under the same HPLC conditions.

Elderflower extraction protocol for in vivo administration

The N4FC sample (without the peduncle) was used to obtain a mother tincture sample, which compared with N4FU had a higher content in the routine. $100 \mathrm{~g}$ of finely ground N4FC was used, to which $1200 \mathrm{~mL}$ of ethanol was added, resulting in mother tincture. After a $24 \mathrm{~h}$ rest,

*email: razvancodea@yahoo.com 
measurement of $102.4 \mathrm{~mL}$ volumes was performed with a rotary evaporator Laborata 4010 Digital, Heidolph, the resulting extract being recovered in $32 \mathrm{ml}$ of physiological saline.

\section{Animal models and experimental design}

Gentamicin (GM) is a widely used antibiotic of the aminoglycoside class widely used to treat severe gramnegative germ infections, particularly valuable in sepsis. However, clinical use is limited by the ototoxic potential and the nephrotoxic effects of this drug. Nephrotoxicity was linked to the selective accumulation of gentamicin in the renal cortex [9], especially in proximal renal tubule (50 to 100 times higher concentration compared to the serum) and free radical production [3]. Studies in recent decades have shown that GM-induced nephrotoxicity is characterized by tubular necrosis, especially in the proximal tube. However, GM is believed to increase the production of reactive oxygen species that lead to a deficiency in intrinsic antioxidant activity. Therefore, the use of substances with high antioxidant activity to prevent or reduce different types of nephrotoxicity has been demonstrated $[11,12]$

The animals ( 24 adult, male, Wistar rats) were divided into 4 groups of 8 individuals each. The study was conducted over 10 days and the animals received daily intraperitoneal substances (gentamicin sulfate) and gavage (elderflower extract). The subjects form the control group received only intraperitoneal injections with saline solution $(\mathrm{NaCl} 0.9 \%)$ whereas the ones from the gentamicin group were injected with $100 \mathrm{mg} / \mathrm{kg} /$ day gentamicin sulfate. Individuals from Gentamicin + elderflower extract group were injected daily with $100 \mathrm{mg} / \mathrm{kg}$ of gentamicin and received $1 \mathrm{ml}$ of gavage elderflower extract whereas the ones from the elderflower group received only $1 \mathrm{~mL}$ of gavage extract. All subjects were euthanized on the 11th day of the experiment using the Isoflurane euthanasia room. Blood samples from all individuals were collected in heparinized tubes.

Subsequently, the plasma was separated by centrifugation at $3000 \mathrm{rpm}$ for $10 \mathrm{~min}$ at $4^{\circ} \mathrm{C}$ to determine urea and creatinine concentration. Urine samples were collected by cystocentesis in clear tubes and centrifuged at $1000 \mathrm{rpm}$ for $5 \mathrm{~min}$ at $4^{\circ} \mathrm{C}$ in order to determine the urinary NAG (N-acetyl-beta-D-glucosaminidase) index.

Biochemical analysis: creatinine and urea serum concentrations were measured using the spectrophotometric kinetic method and the Jaffe reaction.

Determination of urine NAG index: urine samples collected from all subjects were centrifuged at $1000 \mathrm{rpm}$ for 5 min at $4^{\circ} \mathrm{C}$ then the enzyme activity was measured by a spectrophotometric colorimetric method. The NAG index was determined using an endpoint spectrophotometric reaction, while the creatinine urinary concentration was determined by a spectrophotometric kinetic reaction using the Jaffe method. The urinary NAG index was calculated using the following equation: NAG index $(\mathrm{U} / \mathrm{g})=$ urinary $\mathrm{NAG}$ activity $(\mathrm{U} / \mathrm{L}) /$ urinary creatinine concentration $(\mathrm{g} / \mathrm{L})$ [10].

Histopatological examination: At the end of the experiment the animals were sacrificed under anesthesia. The abdominal cavity was carefully dissected and the kidneys were gently removed and cut along the mid dorsal line then immediately fixed in 10\% neutral formalin. The tissue was then dehydrated in ascending concentrations of alcohol, cleaned in xylene and finally embedded in paraffin wax at $60^{\circ}$. The paraffin blocks were sectioned at 5-6 $\mu \mathrm{m}$ thickness and stained with Haematoxylin and Eosin. A number of 10 fields for each kidney section were examined with a Olympus BX41 light microscope. Histological lesions were evaluated using the EGTI (endothelial, glomerular, tubular and interstitial) scoring system [11]. The right kidney was frozen at $-80^{\circ} \mathrm{C}$ for oxidative stress determinations.

Statistical Analysis: All data are reported as mean \pm SEM. To suppose the Gaussian distribution, normality distribution was verified by the normality test D'Agoustino and Pearson omnibus. A single ANOVA variance analysis, followed by Bonferroni's multiple comparison testing, was performed for pair comparisons. Pearson's correlation was used to evaluate the correlation, the interpretation was made according to the Colton scale. Statistical significance was established at $p<0.05$ ( $95 \%$ confidence interval). Statistical values and figures were obtained using GraphPad Prism version 5.0 for Windows, GraphPad Software, San Diego California USA.

\section{Results and discussions}

Quantitative evaluation of phenolic compounds in elderflowers

We obtain a value of rutin quantity from frozen flower of S. Nigra $\mathrm{L} 463.20(\mu \mathrm{g} / \mathrm{mL})$, much higher than from dry flower $385.63(\mu \mathrm{g} / \mathrm{mL})$. In table 1 are presented HPLC-UV $270 \mathrm{~nm}$ identiûcation of phenolic compounds in ethanoic extract N4FC.

In figure 1 is presented the standard mixture of Elderflower extract (HPLC UV-270 nm) and in figure 2. the Elderflower extract in ethanol.

Results of histopathological examination of renal tissue samples and markers of kidney disease

In figure 3 are presented the effects of Sambucus nigra extract on blood urea levels in gentamicin-induced nephropathy (mg/dL) (mean).

\begin{tabular}{|c|c|c|c|}
\hline \multirow[b]{2}{*}{ Polifenolics } & Amount of $(\mu \mathrm{g} / \mathrm{mL})$ & & \multirow{10}{*}{$\begin{array}{c}\text { Table } 1 \\
\text { HPLC-UV } 270 \mathrm{~nm} \text { IDENTIÛCATION OF PHENOLIC } \\
\text { COMPOUNDS IN ETANOLIC EXTRACT N4FC }\end{array}$} \\
\hline & & $\begin{array}{l}\text { Total }(\mu \mathrm{g} / \mathrm{mL}) \\
\text { Total amount of } \\
(\mu \mathrm{g} / \mathrm{mL})\end{array}$ & \\
\hline Flavanols & & 13,77 & \\
\hline Catechina & $3.65 \pm 0.40$ & & \\
\hline Epicatechina & $10.12 \pm 1.53$ & & \\
\hline Flavonoli/Flavonols & & 463,20 & \\
\hline Quercetin-3-O-rutinoside (rutin) & $463.20=0.00$ & & \\
\hline Hydroxycinnamic acids & & $\mathbf{5 , 5 3}$ & \\
\hline Cafeic acid & $3.66 \pm 0.05$ & & \\
\hline Feluric acid & $1.87 \pm 0.62$ & & \\
\hline
\end{tabular}



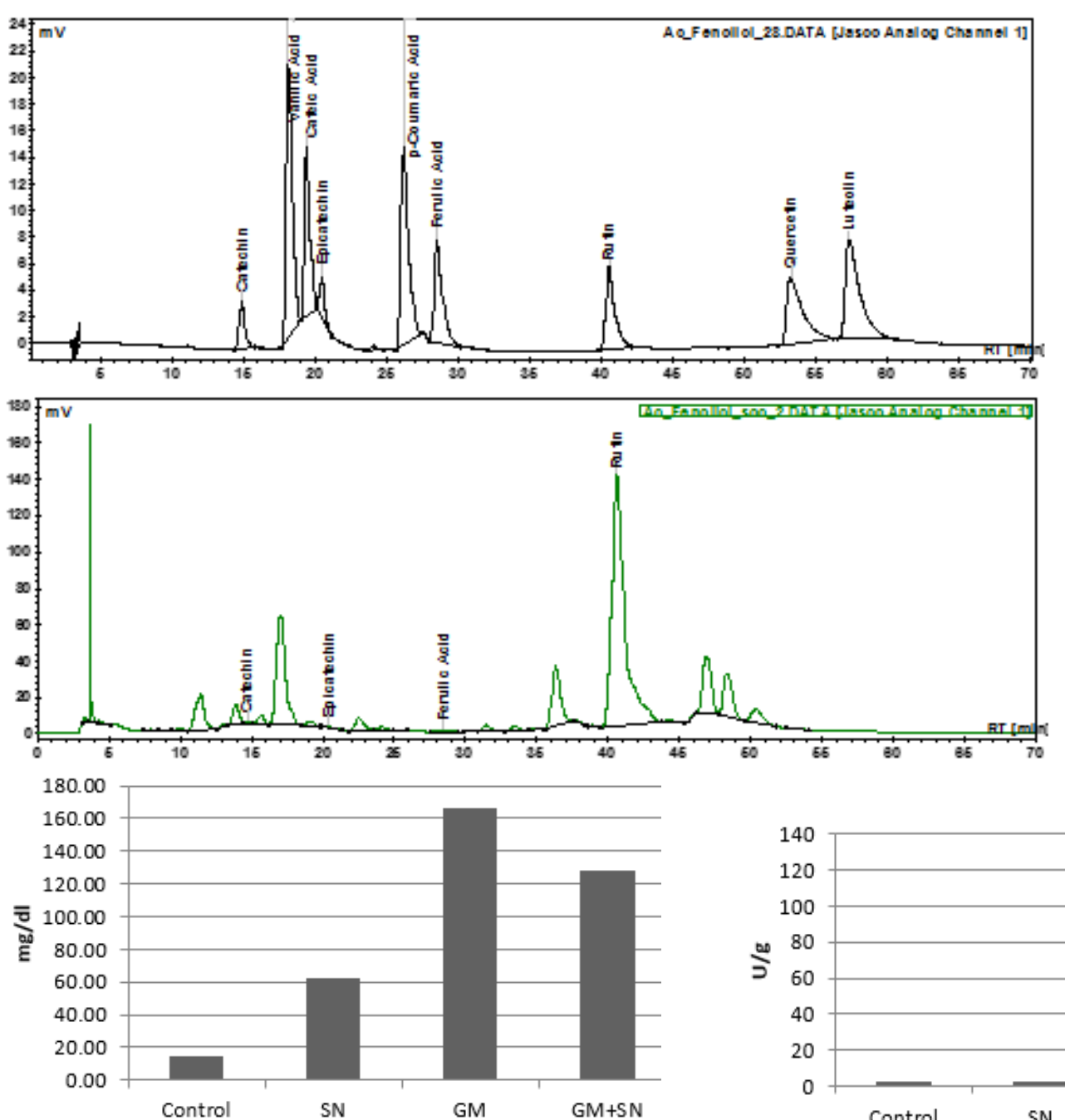

Fig 3 Effects of Sambucus nigra extract on blood urea levels in gentamicin-induced nephropathy ( $\mathrm{mg} / \mathrm{dL}$ ) (mean)

All subjects exposed to gentamicin toxicity remained alive until the end of the study. Blood urea and creatinine levels were decreased in the GM + SN groups compared to the GM group.

In figure 4 are presented the effects of Sambucus nigra extract on blood creatinine levels in gentamicin-induced nephropathy ( $\mathrm{mg} / \mathrm{dL}$ ) (mean), and in figure 5 , the effects of Sambucus nigra extract therapy on iNAG activity in

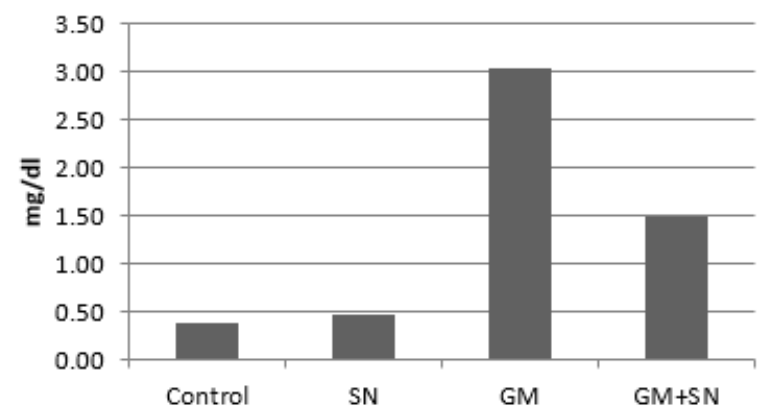

Fig. 4. Effects of Sambucus nigra extract on blood creatinine levels in gentamicin-induced nephropathy $(\mathrm{mg} / \mathrm{dL}$ ) (mean)

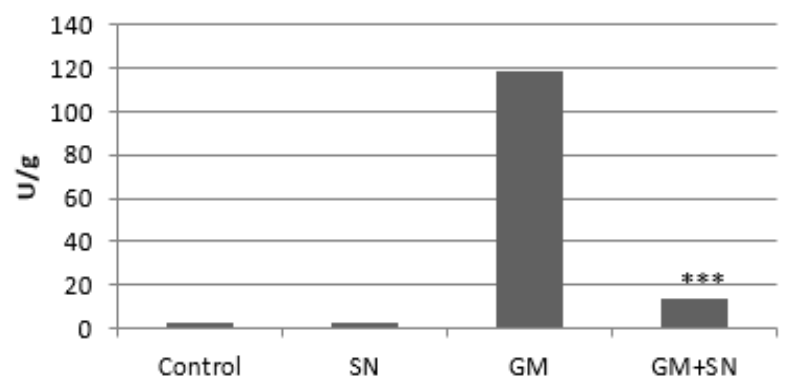

Fig. 5. Effects of Sambucus nigra extract therapy on iNAG activity in gentamicin-induced nephropathy $(\mathrm{U} / \mathrm{g})($ mean) $(* * *=p>0.001)(8$ subjects / group)

gentamicin-induced nephropathy $(\mathrm{U} / \mathrm{g})$ (mean) ( $^{* * *}=\mathrm{p}>$ 0.001) (8 subjects / group).

These findings were confirmed by histopathology, while the GM + SN group showed a decrease in microstructural damage compared to the GM group. Urinary NAG activity was 9 times lower in SN-treated groups $(p<0.001)$ compared to the untreated group (GM) is presented in table 2.

Hsieh et al. [14], in 2013 tests the controversial hypothesis found in previous studies that routine (RT) and quercetin (QT) could act favorably in renal failure. The chemically aglycone quercitin, quercetin glucosides and quercetin rutinoside are closely related but pharmacokinetically these three compounds act differently. To confirm the beneficial, nephroprotective effects of these compounds, authors used doxorubicin (DR) $(8.5 \mathrm{mg} / \mathrm{kg})$ to induce chronic renal disease (CKD) and the treatment administered for 13 weeks, consisted of QT and RT (each $70 \mathrm{mg} / \mathrm{kg}$ body weight per day). The conclusion was that

\begin{tabular}{|l|l|l|l|l|}
\hline & $\begin{array}{l}\text { Tubular } \\
\text { Damage }\end{array}$ & $\begin{array}{l}\text { Endothelial } \\
\text { damage }\end{array}$ & $\begin{array}{l}\text { Glomerular } \\
\text { damage }\end{array}$ & $\begin{array}{l}\text { Tubulo/interstitial } \\
\text { Damage }\end{array}$ \\
\hline Control & 0.1 & 0 & 0 & 0 \\
\hline SN & 0.3 & 0 & 0 & 0 \\
\hline GM & 4 & 2.2 & 2.8 & 3 \\
\hline GM+SN & 2.1 & 1.5 & 1.7 & 2.1 \\
\hline
\end{tabular}

Legend 0 represents healthy tissue, 1 represents minimal lesions,

2 moderate lesions, 3 moderate to severe lesions and 4 severe lesions.

EFFECT OF Sambucus nigra EXTRACT ON HISTOLOGICAL LESIONS INDUCED BY GENTAMICIN NEPHROTOXICITY 
QT determined a better increase in body weight (420 \pm 45) compared to RT, $350 \pm 57 \mathrm{~g} /$ rat. The relationship between kidney and body weight (\%) increases on DR's up to 0.82 as compared to QT 0.35 and RT 0.62 . The glomerular filtration rate is reduced by DR administration to 25.2 compared to RT $48 \pm 11.3$, QT $124.7 \pm 12.8$ and control $191.5 \pm 15.7 \mathrm{~mL} / \mathrm{h}$.

In an experimental model of diabetes in rats, induced by metabolic changes of streptozotocin, the routine acts by remodeling metalloproteinase levels and decreasing the plasma levels of glucose [15].This flavonol is also known by pharmacological activities, including anti-mutagenic, antibacterial, antitumoral [16], antidiarrheal, antiulcerous, anti-inflammatory [17], immunomodulatory [18] . Quercetin, the main flavonol in our diet with a prominent antioxidant character, is ubiquitously found in food. Representing $70 \%$ of an intake of 23-24 mg/day flavones and flavonols in a Dutch diet [19], quercitin consumption may undergo a renal cancer prevention scheme among male smokers, according to a study in southwestern Finland [20].

Han et al. [21], in 2015 develop an experimental model of renal lesion by nephrectomy ( $5 / 6$ of the renal mass) in Wistar rats. Thus, in the study presented by previously mentioned authors, in rats chronic renal failure occurs through nephrectomy $5 / 6$. The treatmentschedule requires oral administration of two routine doses ( 15 and $45 \mathrm{mg} /$ $\mathrm{kg})$ and losartan $(10 \mathrm{mg} / \mathrm{kg})$ for 20 weeks; In addition to the analysis of renal function and histopathological changes, to understand the beneficial action of the routine, the level of TGFâl protein in the kidney was also quantified. The findings of this study show that in addition to demonstrating inhibition of TGF $\beta 1$ expression, routine reduces blood creamy in concentration, proteinuria, and renal oxidative stress. From a histopathological point of view, routine administration improves glomerular and tubulo-interstitial lesion score.

These protective effect against oxidative stress was also signaled for spirulina ethanolic extracts regardless of the concentration by Andrica [22], but these study was made on vitro, until now we don't find one in vivo study for these extracts.

\section{Conclusions}

In frozen elderflower inflorescences the rutin quantity $463.20(\mu \mathrm{g} / \mathrm{mL})$ is significantly higher compared to dry inflorescences $385.63(\mu \mathrm{g} / \mathrm{mL})$.

The administration of Sambucus N. significantly improves the values of urea and serum creatinine in individuals in whom toxic gentamicin nephropathy was induced compared to the control group.

The urinary NAG index was 9 times lower in the Sambucus N. lot compared to the control group, suggesting a significant improvement in EGTI score.
The renal histopathological lesion scored significantly lower values in the group receiving the Sambucus N. extract compared to the control group.

The Sambucus N. extract demonstrates nephroprotective effects in gentamicin-induced renal toxicity, significantly improving its installation and evolution, especially in the renal tubules.

\section{References}

1.PENG, C-C., HSIEH, C-L., KER, Y-B., WANG, H-Y., CHEN, K-C., PENG, R.Y., Mol. Nutr. Food Res. 2012, 56, 1-18

2.BEST, P. J., REDDAN, D. N., BERGER, P. B., SZCZECH, L. A. et al., Am. Heart]. 2004, 148, 230-242

3.BALGRADEAN, M., CINTEZA, E., FILIPOIU, F., JINGA, V., Farmacia, 2013, 61(4):772-780.

4.FRIED, L.F., ORCHARD, T.J., KASISKE, B.L. Kidney Int 2001, 59:260269

5.AL-REJ AIE, S.S., ABUOHASHISH, H.M. ALKHAMEES, O.A., ALEISA A.M., ALROUJ AYEE, A.S., Lipids in Health andDisease 2012, 11:41

6.MLYNARCZYKA, K., WALKOWIAK-TOMCZAKA, D., EYSIAKB, G.P., J ournal of Functional Foods, Volume 40, January 2018, 377-390

7.MIKULIC-PETKOVSEK, M., IVANCIC, A., SCHMITZER, V., VEBERIC, R., STAMPAR, F., FoodChemistry 200 (2016) 134-140

8.FILIP, M., SILAGHI-DUMITRESCU, L., PRODAN, D., SAROSI, C., MOLDOVAN, M., COJ OCARU, I., Key EngineeringMaterials, ISSN: 1662$9795,2017,752,24-28$

9.MORIN, J.P., VIOTTE, G., VANDEWALLE, A., VAN HOOF, F., TULKENS, P., FILASTRE, J.P., Kidney international, 1980, 18(5): 583-590

10.MITCH, W.E., Goldman's Cecil Medicine (Twenty-Fourth Edition), 2012, Pages 810-818, Volume 1

11.ABDEL-RAHEEM, I.T., ABDEL-GHANY, A.A., MOHAMED, G.A., Biol. Pharm. Bull. 2009, 32(1):61-67.

12.TESLARIU, O., AGOROAIE, L., MITITELU-TARTAU, L., ZAMFIR, C., TESLARIU, E., NECHIFOR, M., Farmacia, 2016, 64(2):252-256

13.HERMAN-BONERT, V.S., MELMED, S., The Pituitary (Third Edition), 2011: 83-117

14.HSIEH, C.-L., PENG, C.-C., CHEN, K.-C., PENG, R.Y., J ournal of Agricultural and FoodChemistry, 2013, 61, 7258"7267

15.KAMALAKKANNAN N., MAINZEN PRINCE S.P. Mol CellBiochem 2006; 293: $211-219$

16.KWON, K.H., MURAKAMI, A., TANAKA, T., OHIGASHI, H., BiochemPharmacol 2005, 69, 395-406

17.GUARDIA, T., ROTELLI, A. E., JUAREZ, A. O., PELZER, L. E., Farmaco 2001, 56, 683-687.

18.J ANBAZ, K. H., SAEED, S. A., GILANI, A. H.: Fitoterapia 2002, 73:557563.

19.BOOTS, A. W., HAENEN, G. R., BAST, A., Eur. J. Pharmacol. 2008, 585, 325-337

20.DE VRIES, J.H., JANSSEN, P.L., HOLLMAN, P.C., VAN STAVEREN, W.A., KATAN, M.B., 1997, Cancer Lett. 114, 141-144

21.YU HAN, JIN-SHAN LU, YONG XU, LEI ZHANG, BAO-FA HONG, Int J ClinExpPathol 2015;8(5):4725-4734

22.ANDREICA, F.M., DRAGHICI, G.A., STIOCA, C., PINZARU, I., CORICOVAC, D., CITU, C., DEHELEAN, C., Rev. chim.(Bucharest), 67, 2016, no. 2, p. 289-290

Manuscript received: 21.12.2018 